\title{
Culture Teaching in Foreign Language Teaching
}

\author{
Li Sun \\ School of Foreign Languages, Changchun University of Science and Technology, Changchun, China
}

\begin{abstract}
The purpose of learning a foreign language is to learn to communicate in the target language. For foreign language educators, to develop the learner's intercultural communication competence is to know how to teach foreign culture. Culture teaching in foreign language education is a problem countered by language teachers throughout all universities and colleges in the world. Language is one of the most important carriers of culture and reflects the latter. Without language, culture would not be possible. The basic goal of learning a foreign language is to acquire the communicative competence, while the development and improvement of such competence is to some extent dependent of efficient and scientific teaching approach. Byram has defined the notion of cultural studies in foreign language education and put forward a model for teaching foreign language and culture. Shen Chen has put forward a proposal for developing Chinese foreign language learning learners culture creativity as an attempt to search for away through the difficulties. His cultural creativity refers to a kind of ability that only can be gotten by knowledge acquiring in foreign culture, existed in language and more than language itself, in the process of using such knowledge inter-cultural communication with others and creating new way of thinking for a new way of action. The students can get a further understanding of the target culture which will without doubt promote their understanding and command of competent communication in the target language.
\end{abstract}

Index Terms - language, culture, foreign language teaching, principle, method

\section{INTRODUCTION}

The purpose of learning a foreign language is to learn to communicate in the target language, to learn the customs and traditions of the speech community, and to promote one's study and work. The communicative competence is acquired through the socialization of the speaker. A person, from an ignorant individual to a social member, must learn the knowledge, skill and conversation so as to adjust himself to the society and qualify himself as a social member. This process is known as the socialization of a man and it goes throughout a man's life. This holds true not only to one's native language but also to his learning a foreign language in that language, as a social product, fully embodies the culture of its speech community and is closely related to the culture of the speck community.

Intercultural communicating means communicating among people come from many and various cultures face to face. For foreign language educators, to develop the learner's intercultural communication competence is to know how to teach foreign culture. Culture teaching in foreign language teaching is a question countered by language teachers throughout all universities and colleges in the world.

\section{LANGUAGE AND CUlture}

\section{A. The Relationship between Language and Culture}

The relationship between language and culture is dynamic. Firstly, language is an important part of culture. It is the primary vehicle by which a culture transmits its beliefs, values and norms. Secondly, language is influenced by culture.

Language is one of the most important carriers of culture and reflects the latter. If there is no language, culture would not be known. On the one hand, culture is the basis and one of the most important attributes of language and exerts great influence on the latter. If there is no culture, language will be like water without a source or a tree without roots.

\section{B. The Relationship between Culture and Foreign Language Teaching}

In foreign language learning, linguistic transfer refers to the effect of one language, usually the native language on the learning of another usually the target language. This is also a common strategy employed by foreign language learners. They often use native language patterns or rules in learning target language, which results in errors or inappropriate forms in the target language. This is called negative transfer, also known as interference. Language is inextricably bound up with culture. Cultural values are both reflected by and carried through language. Accordingly, it is inevitable that the way of thinking and expressing influenced by the native culture will be unconsciously transferred to the target language during the intercultural communication. That is the cultural transfer. As a matter of fact, the most difficult thing for the language learners to deal with in their study of the foreign language is not the linguistic forms or grammar, but the cultural difference. In the process of cognition of the world, people always store the schemata into their brain, schemata can be compared to an immerse system of files in one's brain, where you can classify and store you brain and individual knowledge and experience. After receiving some new information, the brain will set up a new schema to store it or put it in an established schema of the same class. Cultural schema refers to the knowledge structure 
based on cultural knowledge. The teaching of cultural knowledge and the establishment of cultural schema will be of great help to the learners' linguistic comprehension and expression. Once needed, the cultural schema stored in one's brain will be used by the students to get rid of the obstruction and solve the problem resulting from cultural differences. Cultural schemata are of vital importance for many aspects of the foreign language learning.

\section{Communicative COMPetence}

Intercultural communication focused on what occurs when the source and the receiver are in different contexts or cultures. Becoming a competent intercultural communicator means being effective in communication with those of divers cultures and groups. The first judgment refers to the ability to produce sentences which are grammatical. The second judgment refers to the ability to produce sentences which are feasible or psychologically acceptable. The third judgment refers to the ability to use correct forms of language in a specific socio-cultural context. The forth judgment is about the occurrences of the linguistic forms.

Communicative competence is the ability to achieve certain communicative aims by various possible linguistic or non-linguistic means. The communicative competence is far more than the grammatical competence of an ideal speaker and it is a highly complex ability. The acquisition of communicative competence in the mother tongue is a natural process of socialization, which has much to do with the whole social activities and social environment. For native speakers, there also exist different degrees of communicative competence. As far as communicative competence in a foreign language is concerned, the training of it takes time and efforts. The basic goal of learning a foreign language is to acquire the communicative competence, while the development and improvement of such competence is to some extent dependent of efficient and scientific teaching approach. Communicative approach takes the development of communicative competence as the main objective of foreign language teaching, with less focus on the correctness of linguistic structure but more on the getting through of meanings, especially the speaker's abilities of interpretation, expression and negotiation in communication. When we communicate, we use the language to accomplish some function such as persuading or protesting, which should be carried out within a social context. Communication is a process, and it is not enough for the learners to simple grasp the knowledge of language forms, grammar and function. The learners must be able to use the language to negotiate meaning in communication, and be able to use the language appropriate to a give social context. Communicative approach will fail without the solid foundation of enough knowledge of the language. Communicative approach is of great significance lies in the fact that it attaches more importance to the practical use of the foreign language rather than the structure or grammar of it.

\section{Culture Teaching}

\section{A. Theories on Culture Teaching}

Byram has defined the notion of cultural studies in foreign language education and put forward a model for teaching foreign language and culture. According to him, foreign language educations should include fore fundamental components, namely, language learning, language awareness, culture awareness and cultural experience. By combining the use of learners first language and foreign language through comparative analysis and new cultural experience, Byram believes that will provide an integrative approach for teaching and learning language and culture. He shared Buttjes's view about cultural content as a prime motivator for language learning.

According to Kramcsh, the teaching of culture in foreign language has taken two main directions: one has focused on cultural information, statistical information, institutional structures and facts of civilization, highbrow information. The classics of literature and arts, lowbrow information, the foods, fairs, and folklore's of everyday life, the other has been to situate culture within an interpretive framework, taken from cross-cultural psychology or cultural anthropology, using universal categories of human behavior and procedures for making sense of foreign reality.

By summarizing theories above, Shen Chen has put forward a proposal for developing Chinese foreign language learning learners culture creativity as an attempt to search for away through the difficulties. The practice of this proposal des includes students encountering new knowledge, and being exposed to new cultural experiences, which should be related to what is already known and experience. The notion of cultural creativity has its foundation in the Chinese cultural context although it draws from current western thinking on language education. It aims to links knowledge and ability throughout the process of learning. It demands and understanding of how knowledge is the basis of ability, which in turn is the source on developing new knowledge. By focusing on learning to know, to do and to interact.

\section{B. Cultivation of Cultural Awareness}

Indeed, we can scarcely imagine learning a foreign language, say English, without acquaintance with the American Dream, the Lost Generation, frontier and so on. Undoubtedly, the belief that language teaching of linguistic knowledge has been dominate for a long period of time, even until recently. The students, educated in this approach, though possessing a good command of vocabulary and grammar, turn out to be incompetent in actual communication. Too often we will find native speakers in embarrassment, confusion even anger by questions like: where are you going, have you eaten yet, how much is your salary and so on and so forth. Lack of cultural awareness proves to be a hinderer in 
foreign language learning. If fact, in the 1980's many linguists commenced to advocate the inclusion of culture in language teaching. That is, the culture knowledge directly associated with the target language is to be regarded as first and foremost in foreign language teaching. Aspects of culture involved are as follows:

Firstly, customs. Customs refer to the habits and traditions formed in the daily life and communication of a speech community. Among them are greeting, addressing, gratitude, apologies and departure and so on. The Chinese usually greet each other by where are you going, have you eaten yet, how much is your salary. These greetings are intended to show their concern and intimacy. However, the same greetings may well bring nothing but embarrassment and bewilderment to the westerners. One thing we have to keep in mind is that the westerners have a keen sense of privacy, as a result, resenting any trespass in this regard. In contrast, they usually greet each other by talking about the weather, such as morning, a fine day and so on.

The discrepancy of different nation in social system, custom and ethics lead to that of addressing. Kinship terminology, describing how people in various parts of the world refer to relatives by blood and marriage, is a universal feature of language because kinship is so important in social organization. The Chinese, for instance, makes a finer distinction of kinship. On the other hand, the westerners possess a very limited scope of addressing their relatives such as grandpa, grandma, uncle and aunt.

Chinese people and the westerners also differ in their way of visiting. The Chinese will usually pay a casual visit to their relatives or friends without informing them in advance. The westerners, however, will habitually make a call beforehand to ensure that the host is convenient and ready for their visit. The westerners will drop a hint that they are leaving about a quarter or twenty minutes before their real departure. Then the host sees him out, but only at the door. In contrast, in China, when one of the guests say, it is getting late, he in fact is implying that the host and the hostess need a rest. The other guests, on hearing this will leave together with him, which will be considered abrupt and impolite by the western people. In addition, the host and the hostess will often see the guests out at the gate and more often on the road. In fact, the Chinese culture and the western culture are so different that it is difficult to make a detailed and complete list of the difference. It is worth nothing that with the exchange of culture, the Chinese especially the young, have begun to adopt some of the westerners way of dealing with people. For example, they will avoid question such as how old are you.

Secondly, psychology. People's psychology may differ in the sense that the values and morals cherished very from nation to nation. As is well-known, individualism and equality are pursued in their nations. They care for frankness or a clear-cut stand of opinion. The Chinese unlike them, value modesty and collectivism than individuality and rather than directness.

Thirdly, historical backgrounds. The term historical background covers the historical development of culture and the accumulation of cultural ethics. Such as in English, we have keep up with the Jones, John Bull, Uncle Sam, the last straw that breaks a camel's back. This kind of knowledge is directly related to some historical figures and events and has to be learnt specifically.

Now that the necessities of teaching culture in foreign language and aspects involved in it have been discussed, a question occur to us: what is the fundamental principle to be obeyed so as to eliminate as many barriers as possible on account of cultural difference. In short, there are three basic principles: firstly, step by step principle. Developing. students cultural awareness should follow the basic sequence of from simplicity to complexity, from surface to depth. The teachers must be conscious of the general level of his students and constantly adjust to it the scope and depth of his cultural teaching. In this sense, we may call for a systematic program for culture teaching. Secondly, appropriateness principle. In cultivating students cultural awareness, we must bear in mind that the ultimate goal of teaching culture is to promote their linguist knowledge and communicative competence. The teacher should strike a proper balance between linguistic teaching and culture teaching to avoid going to the other extreme of rejecting the teaching of linguistic knowledge. Thirdly, as know, culture covers a wide rang including geography, art, custom, history and science. There are sub-branches under each culture. The teacher is to distinguish the mainstream from the less important and to introduce to the students the mainstream.

Novels ,books, and journal. The literature of a particular country is usually a good reflection of its culture. By reading the writings of a specific speech community, the students at the same time of appreciating the masterpiece, can also get familiar with the customs, cultural background reflected the book. For instance, in Gone with the Wind, the students can get information of the American Civil War as well. Films, videos and other electronic aids. These means can present the customs and values of a culture to the students directly and impressively and thus produce an unexpected effect by materializing the western culture. Analysis and comparison. By analyzing and comparing different cultures, the students can get a further understanding of the target culture which will without doubt promote their understanding and command of competent communication in the target language.

\section{C Culture Introduction in Language Teaching}

In the past, in foreign language teaching, teachers usually focused on the language points while neglected the importance of culture introduction in language teaching, so most students know a great many of words and grammar knowledge well, but they lacked the ability to use the language properly. When such students communicate with foreign people, they may make a lot of mistakes. For example, when they meet foreigners, they may ask questions like 'how old 
are you, are you married, how much do you earn'. Such questions made foreign people embarrassed, because they do not ask these questions in their own country. These questions are very personal for them. Although we often ask such questions in our country when we chat with people. In our country, when we meet some acquaintance, we may say 'where are you going', so when students meet foreign teachers, they may ask such questions too. This question as a greeting, is very normal for us Chinese, while in English speaking countries, it is not polite, its personal question too. Why students made such mistakes? Because they do not know the foreign culture, they just know the language, the grammar. It is not enough for language study obviously.

Because of the culture difference, students also made mistakes when they just translates their native language and foreign language to each other. For instance, in English they say 'eat like a horse', but some students may say 'eat like a wolf and a tiger'. So if students don't know the culture background behind the language, they can not understand and use the language well. In foreign language teaching, teacher should not only let students know the basic knowledge of the language, the grammar, but also the culture knowledge. So students may develop a good thinking habit while they use the foreign language, that is our goal while teaching.

Through the teaching experience, I think while give the culture background knowledge, we should firstly learn enough before teaching. We should know politics, economics, geography, history, art, religion, literature and other aspects of the social life. And for the language part we should learn the everyday language, idiom, proverbs because they reflect the culture behind the language. We can get these knowledge by reading books, movies, literature, communicating with foreign friends and so on. Secondly, in our country we don't have course to introduce foreign cultures for non-English major students, when we explain language points and text we should give the culture background at the same time. Thirdly, compare the contrast between the native language the foreign language. In the teaching, we should not only introduce the culture knowledge, but also we should compare the difference between the two languages, so students can the foreign culture clearer.

Words are very important carrier of the culture information, all kinds of culture features can be reflected in the words. Some word have positive meanings in one language while negative meanings in another language. For example, in Lesson from Jefferson, there is a word 'statesman', when teachers explain this word, they can put this word and the word 'politician' together, compare these two words. When these two words are used in American English, 'politician has negative meaning, while 'statesman' has not. Through such comparison, students can know Thomas Jefferson better. And, in Lady Hermits Who Are Down but not Out, there is word 'lost dog', the word dog in Chinese usually with negative meaning, means some one bad, while in English, it is a good word, means loyal, lucky, friends. So when we have this text, teachers should explain this word clearly, so students can understand what the author really want to express. Students often meet sentences with much culture information, as this time, teachers give the cultural background knowledge, in this way, students can understand the sentences better and have a foundation for them to understand the whole text. For example, in A Miserable, Merry Christmas, if students do not know the culture information about story about Christmas or about the Santa Claus and how Santa Claus give children the gifts through chimney, they will not understand the sentence, no candy, there ought to be something to fill your stocking with , and Santa Claus can't put a pone into a stocking? And the sentence, he could not lead a pony down the chimney. The structure of these sentences are simple, but if students do not know the culture information, they can not understand the meanings of these sentences. And in Why I Teach, there is such a sentence, being a teacher is being present at the creation, when the clay begins to breathe. When students read this sentence, they do not know what the author is saying. Teachers should give them the culture information about the Bible. According to Bible, God create people by clay, and God blow the clay, so the clay have life, that is how people was created. Here in this sentence, the author made a metaphor, teachers just like God when help students to be real human. From the examples above, we can know the culture information is so important that teachers must give to the students when necessary, let students know culture meaning not the word meaning only. Miserable, Merry Christmas and The Sampler both talk about stories happen during Christmas, so when we have these two lessons, we should give students the culture background information about Christmas. In Lessons from Jefferson, we should introduce Jefferson, let students know Jefferson is the writer of the Declaration of Independence, let students know who is Jefferson and the information about the Declaration of Independence and American history in this period. In the Death of Hitler, we can add information about the World War Two.

From the angle of the second language acquisition, according the language processing mode, learnig starts from the controlling process, learners learn the dominant language knowledge through practicing and exercising, dominant language knowledge changes to recessive language knowledge. Through culture information introduction, the second language learner will focus on the contrast between the native language and the second language and practice, so the culture knowledge of the second language will become the recessive knowledge for the second language learners. So the intercultural communication can be made smoothly.

\section{CONCLUSION}

Needless to say, the exploration in this paper of how teach foreign culture in foreign language education only touches a limited number of issues. Rather than giving a best approach to teach culture through foreign language teaching in China, we have just suggested several suitable ways to teach. Actually, it is a very difficult task for us Chinese foreign 
language teachers to find a best suitable way to foster the learners intercultural communicative competence by teaching foreign culture. The close interaction of language and culture justifies the cultivation of cultural awareness in foreign language teaching as well as challenges the traditional teaching approach centered on the teaching of linguistic knowledge. The teaching of culture knowledge will undeniably promote communicative ways and methods. The paper through a brief discussion of the relation between language and culture, the principle involve in cultivation of cultural awareness and the approaches to develop cultural awareness, aims at a tentative exploration into the modern teaching method of foreign language teaching. At the same time, attention should be given that cultural awareness, through important and indispensable in foreign language teaching, can not be so overemphasized as to neglect the teaching of linguistic knowledge. The proportionate combination of the two is delicate yet to be appreciated.

\section{REFERENCES}

[1] Deng Yanchang \& Liu Runqing. (1989). Language and Culture. Beijing: Foreign Language Education and Research Press.

[2] Hu Zhuanglin, Liu Runqing \& Li Yanfu. (1988). Linguistics: A Course Book. Beijing: Beijing University Press.

[3] Qin Xiubai. (1988). EFL Learning and Culture Acquisition: Intercultural Communication. Shanghai: Shanghai Translating Press.

[4] Yalden Janice. (2000). Principles of Course Design for Language Teaching. Shanghai: Foreign Language Teaching and Research Press.

[5] Yule George. (2000). The Study of Language. Shanghai: Foreign Language Teaching and Research Press.

[6] Zhu Weifeng. (1997). A Survey on Cultural Differences Foreign Language Teaching and Research, 1, 52-58.

Li Sun was born in Jilin, China in 1978. She received her Master degree in foreign linguistics and applied linguistics from Changchun University of Science and Technology, China in 2005.

She is currently a lecturer in School of Foreign Languages, Changchun University of Science and Technology, Changchun, China. Her research interests include linguistics and teaching methodology. 